\title{
Editorial: Participating in the forensic engineering circle of knowledge
}

Brian Neale CEng, FICE, FIStructE, HonFIDE

Independent Consultant; Executive Secretary, Hazards Forum, Cheshire, UK

This editorial explores some of the stimulating benefits of being part of the exciting community of forensic engineering, which is continuing to develop internationally, across the continents. A common interest bonds the participants in this community a wish to see a better-performing constructed built environment through examination of examples that have fallen short of expected specifications. An important rider to this is that interest is also developed to include the crucial dissemination of knowledge realised from the forensic investigations so that others may learn from them. Further, a number of references are given that will enable the reader to find out much more and to see ways of both receiving information and contributing to the ever-growing bank of published materials on the topics, only some of which are cited in this editorial. To stimulate interest further in those eager to participate in this international community, mention is made of two events that are being planned for 2012 and 2013 where there will be further dissemination of experiences in forensic engineering. Thus, the value of information exchange, or the sharing of experiences, within the forensic engineering and wider communities is explored - with the circle of knowledge enhanced still further.

The sharing of experiences of how well the built environment performs is a practice that has been developing for a number of years and, during the last decade in particular, has developed more rapidly, and on a wider, global scale.

These experiences are largely based on investigations into performance, which may be for a number of reasons. The outcomes can be used in many ways. The rigour of such investigations should be commensurate with need and are commonly undertaken by specialists who are often engineers. The professionalism of those investigations is enhanced by the rigour with which they are undertaken and with the knowledge that is applied at the time, and perhaps afterwards. These could be called forensic investigations, particularly as the quality of such work could be suitable for use where there may be some kind of legal activity. A feature of the credibility of investigating forensic engineers is the need to be current with their knowledge, including the techniques applied. This enables a pertinent service to be given, based on the investigations and associated interpretations of the findings, the outcomes of which may be tested in a legal 'theatre'.

How do such practitioners ensure that their knowledge is current? A principal way surely has to be in sharing experiences. Thus the value of sharing experiences, and hence of information exchange, about the performance of the built environment, as well as how to investigate those performances is crucial. Such activities have been shown to benefit the forensic engineering community in particular and also the wider engineering community.

This in turn can be seen to benefit clients and society as a whole. Indeed, it could be seen as a prime example of how society relies, perhaps unknowingly, on professional engineers and their expertise for the public to go about their day-to-day lives with complete safety and reliability - usually - where this relates in particular, perhaps, to the use of the infrastructure.

Occasionally - very occasionally - there are 'dips' in performance of the built environment. However, some of these 'dips' may not directly affect the public or the use of a particular facility. These 'dips' may occur, for example, before a facility is brought into use, such as when it is being constructed, or perhaps being refurbished or renovated before returning to an augmented, upgraded and renewed state. Whereas those 'dips' may lead to a delay in facilities being brought into use or returning to use, other performance shortcomings may occur during use and may not even be noticed by the users. For example, users may not notice discolouration of surfaces, perhaps of walls or ceilings. A question to ask, however, is why has this occurred? That discolouration will have happened for a reason - perhaps reaction with compounds or elements in the base material, perhaps fungal growth, perhaps water ingress or perhaps for some other reason or combination of reasons. It may lead to health problems in time for the users and also those maintaining the facility, or perhaps lead to future safety issues which could be latent as they develop. On the other hand there may be no potential future problems, other than colours may not match as planned. 
Such failures, for they are failures, may affect the value of facilities, even if they do not have identifiable future health or safety connotations. However, the prognosis may be much more serious.

At the other end of the spectrum, there are dramatic catastrophic collapses which grab headlines and act as societal image-formers of those professionals involved in some way with the built environment. Those involved are many and could include some or all of the following: constructors, materials manufacturers, designers, project managers, funders (often referred to as clients), procurers, specifiers, code writers, trainers, teachers, facility managers, maintainers and not forgetting the users, of course. Others such as insurers, loss adjusters, legislators and enforcers may also find themselves drawn into debates about what may have happened in particular incidents. Are you one of the foregoing?

How best can the forensic engineering community help? It can help to ascertain reasons for 'dips' in performance by proficient investigation, following which the investigating person or team should be able to advise on the cause or causes. This in turn enables the most effective solution options to remediate the failure to be proffered. A further step is to take forward into the forensic engineering community the knowledge gained. This, however, can sometimes encounter 'stumbling blocks' from clients, their insurers or perhaps enforcement agencies, which may at best delay knowledge being promulgated, or at worst prevent the lessons being promulgated at all. In a nonattributable mode, however, outcomes can go forwards to enhance better practice by perhaps being implemented in codes, standards and perhaps legislation, for example.

Where does this take us? We can see two broad aspects that take us to what could be described as a 'circle of knowledge', where the first is the dissemination of knowledge (such as from investigations) and the other is learning from the experience of others. There is a family of options, or tools, available to be considered for this 'giving' and 'receiving' of knowledge.

These options have expanded in recent years, both in quantity and geographical areas owing to the widespread recognition of the need for such vehicles and, of course, their use. One example is journals, where the Institution of Civil Engineers (ICE) now joins the family with this second issue of a new regular quarterly publication on forensic engineering. A further example is conferences where ICE has so far held four international events since 1998. The American Society of Civil Engineers (ASCE) has so far held five congresses - at three-year intervals. Each of the foregoing nine events has had it own dedicated publication that captures the proceedings (Bosela and Delatte, 2006; Bosela et al., 2003; Chen et al., 2009; Neale, 1999; 2001; 2005; 2008; Rens, 1997; Rens et al., 2000) and thus making them available for future reference - disseminating the knowledge. Both ICE and ASCE are currently planning the next event in their respective series (see www.asce.org/conferences and www.iceforensicengineering.com, respectively). Further, conferences in countries such as Taiwan, India and other European states have helped to widen the community internationally. Also, further information can be found in The Journal of the Performance of Constructed Facilities (JPCF), published by ASCE in a regular series.

Another source for in-depth accounts of investigations, with their outcome, can be seen in official reports of incidents and perhaps associated hearings, public inquiries or court proceedings, such as that for the well-known partial collapse of the multi-storey tower block in London known as Ronan Point (HMSO, 1968). Readers of such inquiry reports will be able to see original accounts of the failures rather than 'second-hand' information which may be from papers or articles, for example, which in turn may not have sourced original material - and perhaps have an interpretation that could be considered in a different way. Sourcing original material helps to avoid repetition of inaccuracies that are sometimes promulgated and can enter the accepted 'truth' - even of well-known incidents. As an example - and referring back to Ronan Point - how many readers can answer accurately the question: 'How many floors suffered partial collapse after the initial blast?' A supplementary question, which is sometimes inaccurately written up is: 'In which room did the explosion occur'. Why not try a quiz among your colleagues to ascertain their impression of the answers to those two questions?

Further sources of helpful publications, which could be missed in database searches, include those without 'forensic engineering' in the title, but are worth looking out for. Disasters: learning the lessons for a safer world by Eves (2010), includes references of the type of reports referred to above. The title may be considered rather dramatic, but it does capture one's attention and encapsulates an essential principal, as discussed in this editorial. A review of this book can be found on page 99 .

There is more, however. How many of us look outside the expected sources of information, for example, especially when one considers that civil engineering, with all its component topics, interacts with many other disciplines - engineering and otherwise? As an example, an organisation based in the UK, the Hazards Forum (see www.hazardsforum.org.uk) brings together many disciplines 'to provide a focal point in which engineering features in the mitigation and reduction of both man-made and natural hazards and disasters'.

Participation in this exchange of information all helps to underpin competence, enhance the standing of forensic engineers, and thus make more credible the outcomes of 
investigations. Debate and discussion could be regarded as an essential component of that participation. It is gratifying to see, therefore, that in this second issue of Forensic Engineering we see a discussion of the paper on engineering safety published in issue one (Blockley and Edwards, 2011). Further debate is encouraged on this fundamental topic - and perhaps alternative ways of perceiving this aspect of our world.

Returning to this issue, a diverse range of briefings and papers are included. The briefings help us to consider three topics. In 'How can forensic engineering help improve future practice?', Matthews (2011) considers a recurring theme in the community and one which in this case includes consideration of the blend of sustainability and climate change. 'Forensic engineering through the microscope' takes us into the world of petrographic examination, which, as Ingham (2011) suggests, is 'one of the most powerful laboratory techniques available to the forensic engineer'. The third briefing on the ASCE forensic engineering symposium brings an overview of the many topics that were considered at the latest tri-annual symposium in New York City in June last year. Ratay (2011a) describes a symposium held in a way that might inspire others to consider an alternative format for such events.

The international flavour continues in the papers featured in this issue. In 'London Underground: nineteenth century railway, twenty-first century standards', Bessant (2011) takes us into the fascinating world of what could, perhaps, be described as 'economic forensic engineering' dealing with older Victorian infrastructure with regard to its suitability for current operating environments, and perhaps vulnerability in those environments. Although the topic of 'Fire-induced structural failure: the World Trade Center, New York' has been the subject of other papers in the years since the events on 11 September 2001, the work presented in this paper by Torero (2011) does not aim to add to previous studies, but 'focuses on putting the investigation of the WTC collapses in the context of a methodology that enables the investigation of complex failures'. This paper could be seen as complementing Ingham's paper 'Forensic engineering of firedamaged structures' (Ingham, 2009).

In the paper 'The forensic structural expert consultant/witness - US practices', Ratay (2011b) presents his overview of the qualifications, roles, ethics and scope of the work of expert consultants/witnesses who are retained after failures of structures in the USA. Overviews of readers' experiences from other legal systems of such matters would contribute to the wider understanding of the variety of approaches. A case study paper of 'Investigation and remediation of a storm-damaged Pacific port' (Wallis and Sandeford, 2011) brings to mind the importance of recognising and understanding the risks associated with reducing some design criteria when designing structures for a reduced (or limited) design life. Wallis and
Sandeford consider many issues, including the actions to be considered and the likely return periods as they might affect infrastructure projects.

In conclusion, as part of this expanding 'circle of knowledge' in the forensic engineering community, all reading this journal could be considered part of the community, even if exploring the topic of forensic engineering for the first time. A question to ask is - how many readers will now consider sharing some of their own experiences with this stimulating community, perhaps again?

\section{REFERENCES}

Bessant GT (2011) London Underground: nineteenth century railway, twenty-first century standards. Proceedings of the Institution of Civil Engineers, Forensic Engineering 164(2): 59-67. doi: 10.1680/feng.2011.164.2.59.

Blockley DI and Edwards L (2011) Discussion: Engineering safety. Proceedings of the Institution of Civil Engineers, Forensic Engineering 164(2): 97. doi: 10.1680/feng.2011.164.2.97.

Bosela PA and Delatte NJ (eds) (2006) Proceedings of the 4th Congress on Forensic Engineering, Cleveland. American Society of Civil Engineers, Reston, VA.

Bosela PA, Delatte NJ and Rens KL (eds) (2003) Proceedings of the 3rd Congress on Forensic Engineering, San Diego. American Society of Civil Engineers, Reston, VA.

Chen S, Diaz de Leon A, Dolhon AM, Drerup MJ and Parfitt MK (eds) (2009) Proceedings of the 5th Congress on Forensic Engineering - Pathology of the Built Environment, Washington. American Society of Civil Engineers, Reston, VA.

Eves D (2010) Disasters: Learning the Lessons for a Safer World. IOSH, Wigston.

HMSO (1968) Official report: Report of the inquiry into the Collapse of Flats at Ronan Point, Canning Town. HMSO, London.

Ingham J (2009) Forensic engineering of fire-damaged structures. Proceedings of the Institution of Civil Engineers Civil Engineering, Special Issue 162(5): 12-17.

Ingham J (2011) Briefing: Forensic engineering through the microscope. Proceedings of the Institution of Civil Engineers, Forensic Engineering 164(2): 55-56. doi: 10.1680/ feng.2011.164.2.55.

Matthews S (2011) Briefing: How can forensic engineering help improve future practice? Proceedings of the Institution of Civil Engineers, Forensic Engineering 164(2): 51-54. doi: 10.1680/feng.2011.164.2.51.

Neale BS (ed.) (1999) Proceedings of the International Conference on Forensic Engineering - A Professional Approach to Investigations. Thomas Telford, London. Neale BS (ed.) (2001) Proceedings of the 2nd International Conference on Forensic Engineering - The Investigation of Failures, London. Thomas Telford, London. 
Neale BS (ed.) (2005) Proceedings of the 3rd International Conference on Forensic Engineering - Diagnosing Failures and Solving Problems, London. Taylor and Francis, London. Neale BS (ed.) (2008) Proceedings of the 4th International Conference on Forensic Engineering: From Failure to Understanding. Thomas Telford, London.

Ratay RT (2011a) Briefing: ASCE forensic engineering symposium. Proceedings of the Institution of Civil Engineers, Forensic Engineering 164(2): 57-58. doi: 10.1680/ feng.2011.164.2.57.

Ratay RT (2011b) The forensic structural expert consultant/ witness - USA practices. Proceedings of the Institution of Civil Engineers, Forensic Engineering 164(2): 79-86. doi: 10.1680/feng.2011.164.2.79.
Rens KL (ed.) (1997) Proceedings of the 1st Congress on Forensic Engineering. American Society of Civil Engineers, Reston, VA.

Rens KL, Rendon-Herrero O and Bosela, PA (eds) (2000) Proceedings of the 2nd Congress on Forensic Engineering. American Society of Civil Engineers, Reston, VA.

Torero JL (2011) Fire-induced structural failure: the World Trade Center, New York. Proceedings of the Institution of Civil Engineers, Forensic Engineering 164(2): 69-77. doi: 10.1680/feng.2011.164.2.69.

Wallis R and Sandeford P (2011) Investigation and remediation of a storm-damaged Pacific port. Proceedings of the Institution of Civil Engineers, Forensic Engineering 164(2): 87-95. doi: 10.1680/feng.2011.164.2.87. 